\title{
Determination of a melt-onset date for Arctic sea-ice regions using passive-microwave data
}

\author{
Mark R. Anderson \\ Department of Geography, 324 Avery Hall, University of Nebraska, Lincoln, NE 68588-0135, U.S.A.
}

\begin{abstract}
Although the formation and melt of sea ice are primarily functions of the annual radiation cycle, atmospheric sensible-heat forcing does serve to delay or advance the timing of such events. Additionally, if atmospheric conditions in the Arctic were to vary due to climate change it may have significant influence on ice conditions. Therefore, this paper investigates a methodology to determine melt-onset date distribution, both spatially and temporally, in the Arctic Ocean and surrounding sea-ice covered regions.

Melt determination is made by a threshold technique using the spectral signatures of the horizontal brightness temperatures $(19 \mathrm{GHz}$ horizontal channel minus the $37 \mathrm{GHz}$ horizontal channel) obtained from the Special Sensor Microwave Imager (SSM/I) passive-microwave sensor. Passive-microwave observations are used to identify melt because of the large increase in emissivity that occurs when liquid water is present. Emissivity variations are observed in the brightness temperatures due to the different scattering, absorption and penetration depths of the snowpack from the available satellite channels during melt. Monitoring the variations in the brightness temperatures allows the determination of melt-onset dates.

Analysis of daily brightness temperature data allows spatial variations in the date of the snowmelt onset for sea ice to be detected. Since the data are gridded on a daily basis, a climatology of daily melt-onset dates can be produced for the Arctic region. From this climatology, progression of melt can be obtained and compared inter-annually.
\end{abstract}

\section{INTRODUCTION}

Scientific interest in the potential effects of climate change on the polar regions has increased since computer simulations have shown that high latitudes are likely to experience enhanced warming. The response of sea-ice regions to a projected warming has been of particular interest. To decide how snowmelt on the sea ice responds to climate variations, surface snowmelt must be examined. This project is a new approach to determine the date of snowmelt onset for the Arctic sea-ice region using passive-microwave data from the Special Sensor Microwave Imager (SSM/I) platform. Previous work has shown strong variations in the date of the onset of snowmelt on sea ice from passive-microwave remote sensing (Anderson, 1987a, b; Anderson and others, 1985) for different locations and from year-to-year. More recent research using similar passive-microwave techniques on the Greenland ice sheet has determined variations in the date of melt onset and spatial coverage of the melting snow cover (Abdalati and Steffen, 1995; Mote and Anderson, 1995). Results from these studies are used here to produce a new algorithm that detects the onset date of snowmelt on sea ice. This is possible because of the large increase in emissivity that occurs when liquid water is present in the snowpack. The algorithm is suited for the entire Arctic Basin since it works regardless of ice type (ice type was found to be an important factor in detecting melt). Melt onset is correlated with albedo changes. A better understanding of the albedo changes during the early spring and summer will allow computer models to give better estimates for surface energy balances.

\section{ALGORITHM DEVELOPMENT}

Several locations in the Arctic Basin, including first-year and multi-year ice regions (Table 1) were used to develop an algorithm that would represent the onset date of snowmelt. These locations are the same as those used in previous research (Anderson and others, 1985; Anderson, 1987a, b) allowing comparison with prior results. To develop an algorithm, SSM/I passive-microwave brightness temperature $(T B)$ data were obtained from the National Snow and Ice Data Center (NSIDC). These data are gridded into $25 \times$ $25 \mathrm{~km}$ gridcells and archived on CD-ROM. In the development of the algorithm, time series of the TB were analyzed, although an algorithm was not developed solely using an individual passive-microwave channel. For example, the algorithm that detects melt onset on the Greenland ice sheet using a $37 \mathrm{GHz}$ horizontal TB threshold technique (Mote and Anderson, 1995), could not be used because sea-ice TBs vary too much due to the presence of different ice types and open water. In contrast, on the Greenland ice sheet, the snow cover is thick enough that $T B$ signatures are of snow only, and do not reflect the underlying surface.

Time series of total ice $(T I)$ and multi-year ice fraction $(M Y I)$, calculated using the NASA Team Algorithm (Cavalieri and others, 1984), were also examined to detect the onset of melt. As previous research has shown (Anderson and others, 1985; Anderson, 1987a, b) monitoring these 
Table 1. Location sites and melt-onset dates

\begin{tabular}{|c|c|c|c|c|c|c|c|}
\hline \multirow[t]{2}{*}{ Point } & \multirow[t]{2}{*}{$i, j$} & \multirow[t]{2}{*}{ Lal } & \multirow[t]{2}{*}{ Long } & \multirow[t]{2}{*}{ Location } & \multicolumn{3}{|c|}{ Melt-onset date } \\
\hline & & & & & 1989 & 1990 & 1991 \\
\hline 1 & 154,160 & $72 \mathrm{~N}$ & $135^{\circ} \mathrm{E}$ & Laptev Sea (FYI) & 143 & 123 & 129 \\
\hline 2 & 113,163 & $71^{\circ} \mathrm{N}$ & $165^{\circ} \mathrm{E}$ & East Siberian Sea (FYI) & 99 & $92 *$ & $91 *$ \\
\hline 3 & 85,174 & $69^{\circ} \mathrm{N}$ & $176^{\circ} \mathrm{W}$ & Chukchi Sea FYI & 141 & 101 & 142 \\
\hline 4 & 80,188 & $70^{\circ} \mathrm{N}$ & $167^{\circ} \mathrm{W}$ & Chukchi sea FYI) & 96 & 115 & 111 \\
\hline 5 & 160,193 & $80^{\circ} \mathrm{N}$ & $120^{\circ} \mathrm{E}$ & Laptev Sea (MYI) & 169 & 149 & 147 \\
\hline 6 & 230,212 & $72^{\circ} \mathrm{N}$ & $62 \mathrm{E}$ & Barents Sea (FYI) & 104 & 103 & 98 \\
\hline 7 & 132,213 & $83^{\circ} \mathrm{N}$ & $180^{\circ} \mathrm{E}$ & Arctic Ocean (MYI) & 174 & 138 & 158 \\
\hline 8 & 132,214 & $83^{\circ} \mathrm{N}$ & $177^{\circ} \mathrm{W}$ & Arctic Occan (MYI) & 174 & 138 & 185 \\
\hline 9 & 124,234 & $83^{\circ} \mathrm{N}$ & $136^{\circ} \mathrm{W}$ & Arctic Ocean (MYI) & 173 & 157 & 186 \\
\hline 10 & 132,319 & $70^{\circ} \mathrm{N}$ & $60^{\circ} \mathrm{W}$ & Baffin Bay (FYI $)$ & 108 & 115 & 122 \\
\hline 11 & 65,330 & $60.5^{\circ} \mathrm{N}$ & $88^{\circ} \mathrm{W}$ & Hudson Bay (FYI) & 104 & 93 & $97^{*}$ \\
\hline 12 & 66,340 & $59^{\circ} \mathrm{N}$ & $85^{\circ} \mathrm{W}$ & Hudson Bay (FYI) & 117 & $92^{*}$ & 111 \\
\hline 13 & 65,351 & $57^{\circ} \mathrm{N}$ & $82.5^{\circ} \mathrm{W}$ & Hudson Bay (FYI) & 134 & $93^{*}$ & 111 \\
\hline
\end{tabular}

* First date of analysis

parameters gives an indication of melt-onset dates. However, advection of different ice types into the location might give similar results. Therefore, use of $T I$ and $M Y I$ would help define melt onset, but could not be used in a new algorithm.

Several different published ratios, as well as a new ratio, were calculated to assist in detecting the melt-onset date. For example, the polarization ratio $(P R)$ and gradient ratio $(G R)$ from the NASA Team sea-ice-concentration algorithm (Cavalieri and others, 1984) were examined. The expressions for $P R$ and $G R$ are:

$$
\begin{aligned}
P R & =\frac{[T B(19 \mathrm{~V})-T B(19 \mathrm{H})]}{[T B(19 \mathrm{~V})+T B(19 \mathrm{H})]} \\
G R & =\frac{[T B(37 \mathrm{~V})-T B(19 \mathrm{H})]}{[T B(37 \mathrm{~V})+T B(19 \mathrm{H})]} .
\end{aligned}
$$

Analysis of the $P R$ and $G R$ time series showed that these ratios were sea-ice-type dependent In addition, the cross polarization gradient ratio $(X P G R)$ used by Abdalati and Steffen (1995) to show melt on the Greenland ice sheet was also investigated. The XPGR is defined by:

$$
X P G R=\frac{[T B(19 \mathrm{H})-T B(37 \mathrm{~V})]}{[T B(19 \mathrm{H})+T B(37 \mathrm{~V})]} .
$$

The XPGR reduces the dependence of the spatial variability of physical temperatures compared to the single-channel approach of Mote and Anderson (1995). However, the $X P G R$ algorithm, when applied to sea ice, was also found to be ice-type dependent. These factors were determined to be important deficiencies; therefore these ratio algorithms were not pursued in the new algorithm development. Another ratio was calculated using the difference between the horizontal channels 37 and $19 \mathrm{GHz}(X H G R)$ given by:

$$
X H G R=\frac{[T B(37 \mathrm{H})-T B(19 \mathrm{H})]}{[T B(37 \mathrm{H})+T B(19 \mathrm{H})]} .
$$

Similar results were found for the $X H G R$ as were observed with the XPGR algorithm: the $X H G R$ was dependent on ice type.

For all of these passive-microwave methods, it was fairly easy to determine visually the onset of melt because the parameters would start behaving differently. A threshold value for each technique could be set that determined melt onset, allowing the process to be automated. However, the problem with these techniques and their thresholds was that sea-ice type was needed to determine the direction of the parameter change.

The original $T B$ time series were scrutinized further to determine whether other relationships could be observed in the data that might suggest the melt onset and not be dependent on the sea-ice type. A new melt algorithm using the difference between the $19 \mathrm{GHz}$ and $37 \mathrm{GHz}$ horizontally polarized channel ( $H G$ algorithm) was generated and is given by the following:

$$
H R=T B(19 \mathrm{H})-T B(37 \mathrm{H}) .
$$

The horizontal channels reflect a strong dependence on snow conditions during melt. Rapid changes in snow conditions are observed in the TB. During melt conditions, the $T B$ first increase from liquid water within the snowpack, then a decrease occurs because of freeze/thaw cycles increasing the snow grain-size (i.e. Mätzler, 1987; Onstott and others, 1987), allowing the $H G$ algorithm to detect these variations.

A single threshold value was determined by examining regions in the Arctic Basin (Table 1) for three years (1989-91) when the $H G$ algorithm exhibited a change in the $T B$. Time series of the $T B, T I$ and $M Y I$ concentrations, various ratios and the $H G$ algorithm were analyzed for all sites. However, only two locations representing different ice types will be discussed. These two sites were chosen because they represent locations where variations with the algorithm existed and could be analyzed, compared to other sites where the algorithm was more consistent in determining the melt-onset date.

The first location is a first-year-ice region located in the Laptev Sea. The three time series for this location show general trends in $T B$ and ice concentrations that would be expected during the late-winter through summer for a first-year-ice region (Figs 1-3). The $T B$ for all four channels $(19 \mathrm{H}, \mathrm{V}$ and $37 \mathrm{H}, \mathrm{V}$ ) average about $250 \mathrm{~K}$ during the winter period, with little separation between horizontal and vertical channels. After a spring/summer melt period where $T B \mathrm{~s}$ vary greatly, the temperatures are indicative of open-water conditions (i.e. Cavalieri and others, 1984). This is observed in all three years, though large variations take place in the timing of the melt periods. The ice concentrations and ratios also exhibit variations during the melt period. The $H G$ al- 

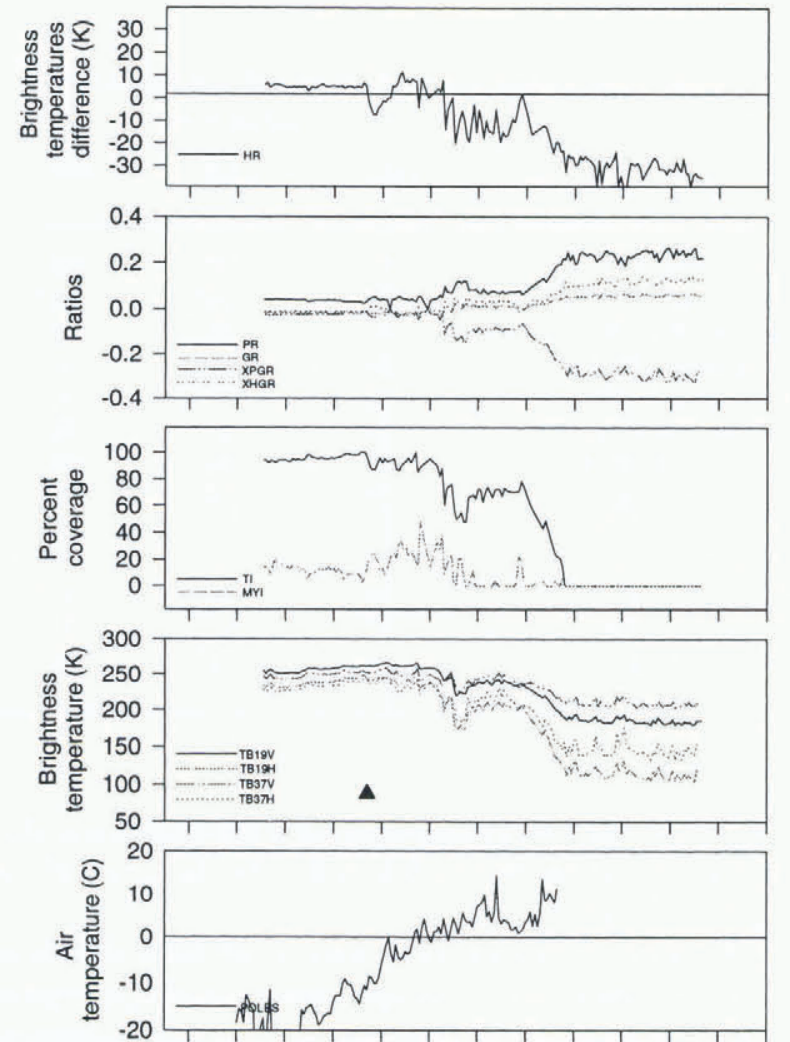

6080100120140160180200220240260280300 Julian Day

Fig. 1. Time-series analysis for a first-year-ice location in the Lapter Sea $\left(72^{\circ} \mathcal{N}, 135^{\circ} \mathrm{E}\right)$ for 1989 . The triangle represents the onset of melt as detected by the HR mell algorithm.
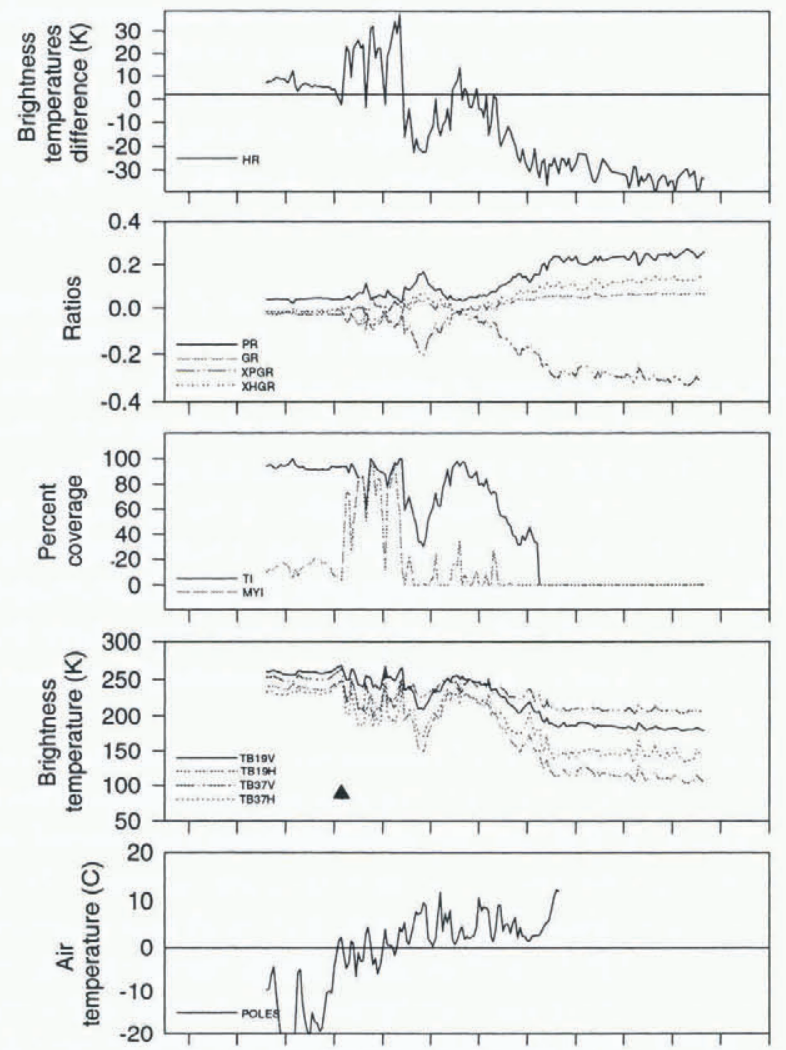

6080100120140160180200220240260280300 Julian Day

Fig. 2. Time-series analysis for a first-year-ice location in the Laptev Sea $\left(72^{\circ} \mathcal{N}, 135^{\circ} \mathrm{E}\right)$ for 1990 . The triangle represents the onset of melt as detected by the HR melt algorithm.
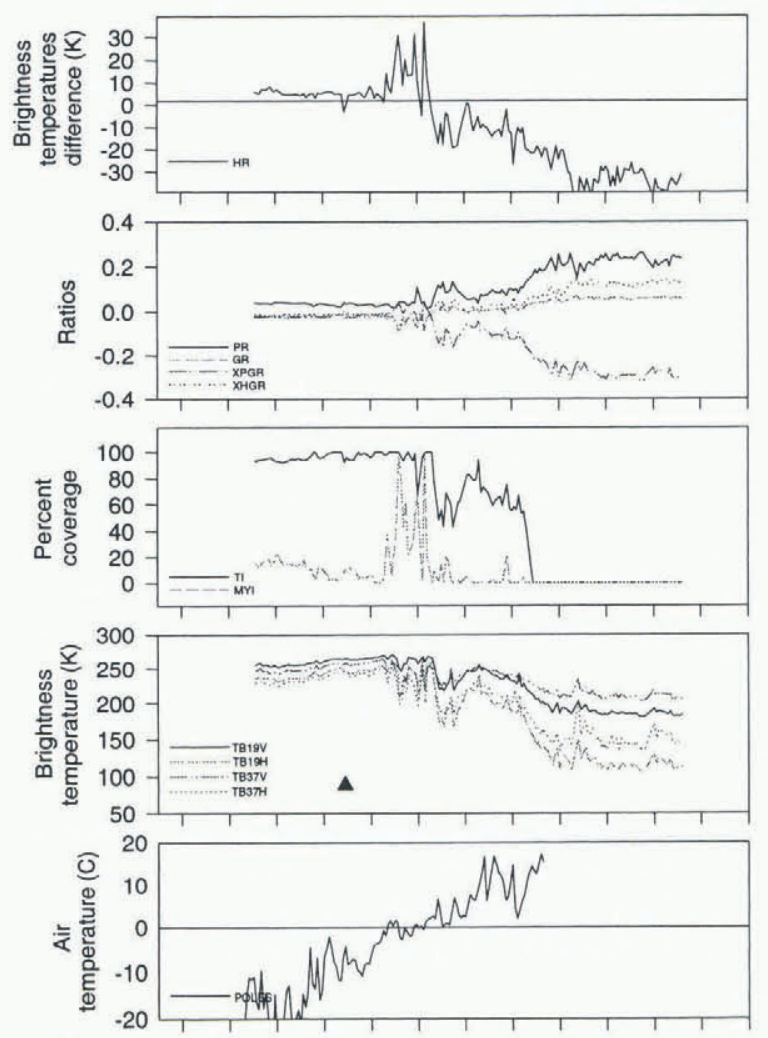

6080100120140160180200220240260280300

Julian Day

Fig. 3. Time-series analysis for a first-year-ice location in the Laptev Sea $\left(72^{\circ} \mathcal{N}, 135^{\circ} \mathrm{E}\right)$ for 1991 . The triangle represents the onset of melt as detected by the HR melt algorithm.

gorithm shows that during the winter period before melt takes place, the difference between the 19 and $37 \mathrm{GHz}$ channels is fairly consistent between 4-7 K. Once melt takes place, the variations in the difference become quite large. However, in all three years the initial change was to increase the $37 \mathrm{H} \mathrm{GHz} T B \mathrm{~s}$, resulting in a decrease in the $H G$ values.

Similar patterns were found for multi-year ice locations. For discussion purposes, one site only will be presented, although others were analyzed. The site, a multi-year-ice location found in the central Arctic Ocean (Table 1), also exhibits general seasonal trends in the parameters for the three years (Figs 4-6). The TBs exhibit three distinct periods: winter conditions with generally consistent temperatures; a melt period where large variations are observed; and summer conditions followed by winter conditions. The multi-year-ice concentrations and various ratios $(P R, G R$, $X P G R$ and $X H G R$ ) also exhibit fluctuations during the melt period. The $H G$ algorithm also shows variations in the $T B$ difference taking place during melt. The $H G$ temperature variations are larger than the ones observed for the first-year-ice regions (Figs 1-3).

Using all sites (Table 1) it was determined that a melt threshold would be assigned when the $H G$ was $\leqq 2 \mathrm{~K}$ with ice concentrations $>15 \%$. When snowmelt takes place the snow cover should become nearly a perfect black-body emitter and the difference between the 19 and $37 \mathrm{GHz}$ channels should be very small. A $2 \mathrm{~K}$ threshold was chosen because of the large SSM/I grid size and inhomogeneities within any grid.

To help determine whether the $H G$ algorithm is detecting the onset of melt, air temperatures have been obtained from the Polar Exchange at the Sea Surface (POLES) data- 

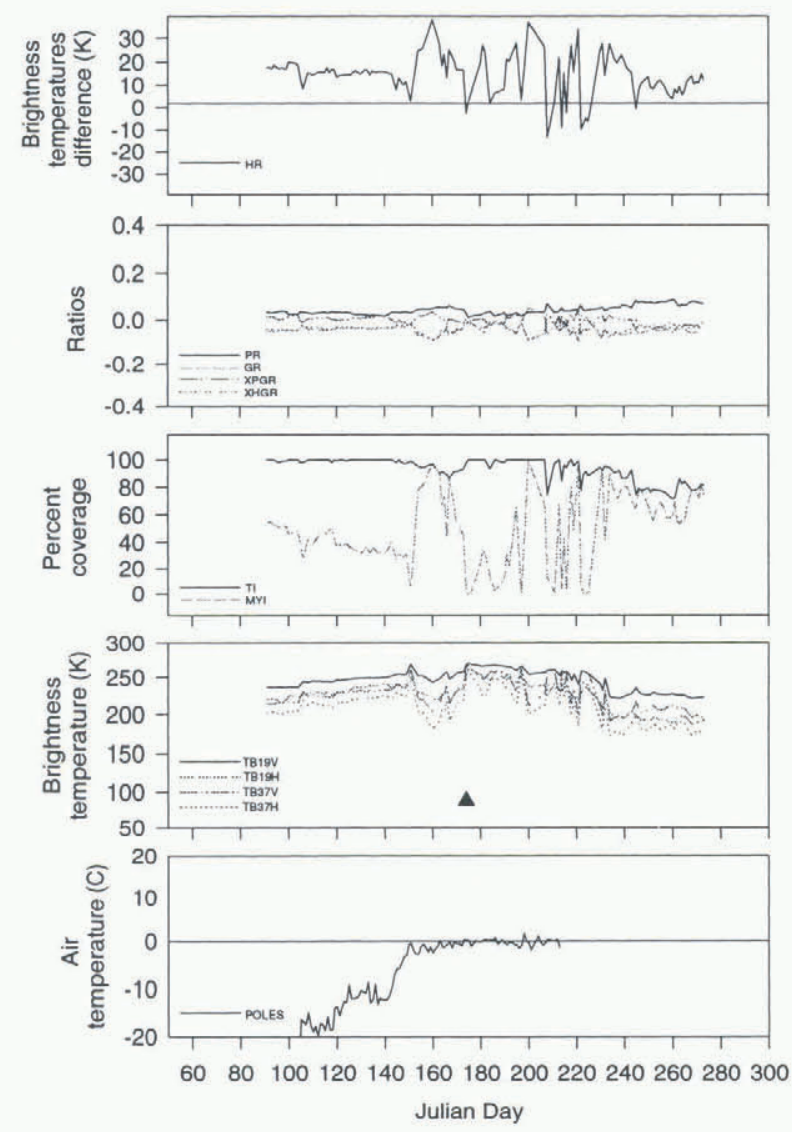

Fig. 4. Time-series analysis for a multi-year-ice location in the central Arctic Ocean $\left(83^{\circ} \mathrm{N}, 180^{\circ} \mathrm{W}\right)$ for 1989 . The triangle represents the onset of melt as detected by the HR melt algorithm.
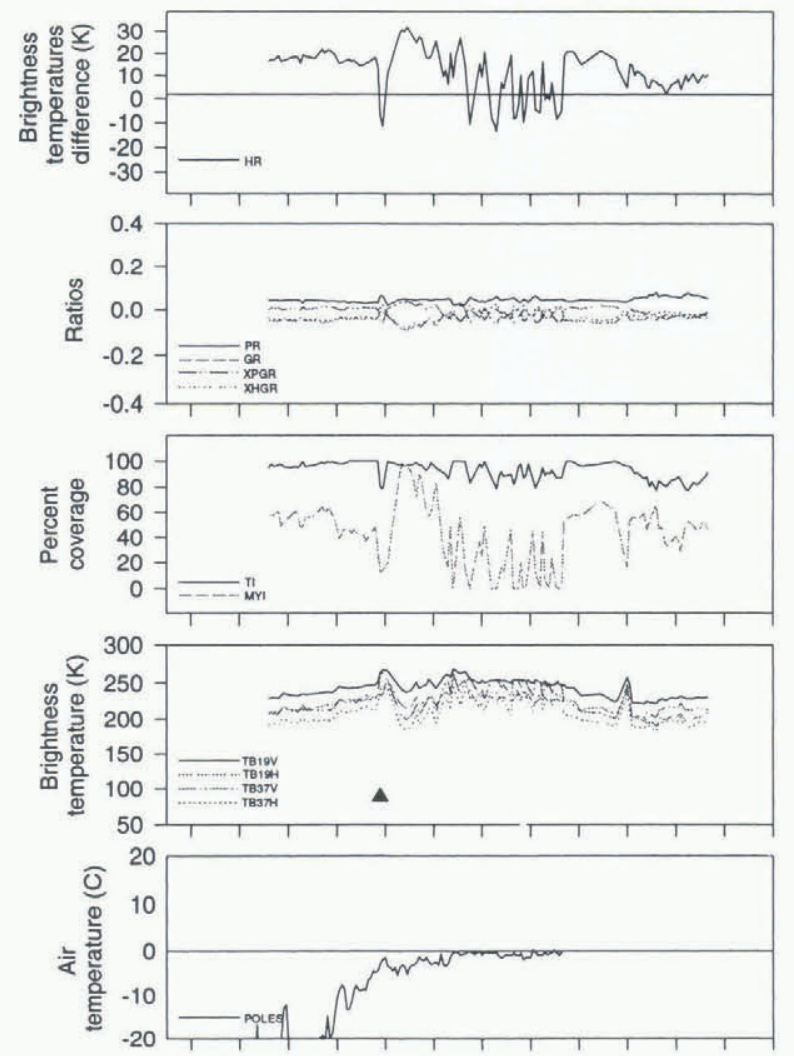

6080100120140160180200220240260280300 Julian Day

Fig. 5. Time-series analysis for a multi-year-ice location in the central Arctic Ocean $\left(83^{\circ} \mathrm{N}, 180^{\circ} \mathrm{W}\right)$ for 1990 . The triangle represents the onset of melt as detected by the HR melt algorithm.
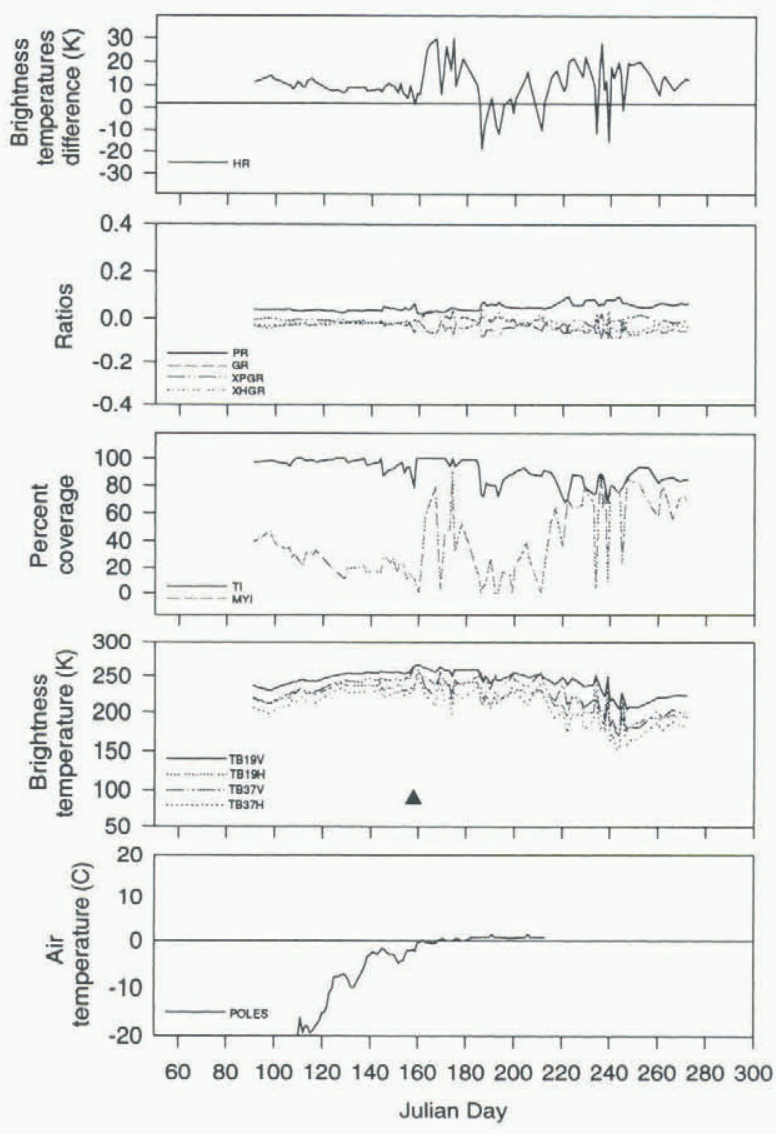

Fig. 6. Time-series analysis for a multi-year-ice location in the central Arctic Ocean $\left(83^{\circ} \mathrm{N}, 180^{\circ} \mathrm{W}\right)$ for 1991 . The triangle represents the onsel of melt as detected by the HR melt algorithm.

set. The POLES temperature data are derived from Arctic buoy data, AVHRR surface temperatures and land observations and averaged over a 24 hour period to correspond to the microwave data. When comparing the $H G$ algorithm's determination of the melt-onset date with the nearest gridpoint of the POLES temperature data, there is a strong association. The $H G$ algorithm indicates melt onset when the POLES data approach or reach the freezing point (Figs 1-6). The best relationships between the air temperature and the $H G$ algorithm are for the multi-year-ice location. It should be noted that multi-year-ice locations might be better depicted by the POLES data because of the way the air temperatures are generated: the POLES data are a combination of buoy, satellite and land surface observations. POLES temperatures are not as reliable for first-year-ice regions, generally located along the coastline, since landsurface temperature observations included in the calculation may not be representative of sea-ice conditions (personal communication from J. Maslanik, 1996).

Generally speaking, whenever a global threshold is applied to a dataset, there will be times and locations when a single threshold will not represent all situations. For example, at the first-year-ice location discussed (Figs 1-3) the $H G$ threshold captures the start of the melt period two out of the three years (1990 and 1991). In the third year (1989), the $H G$ algorithm indicates the melt onset while the temperatures are still well below freezing. However, there is an increase in the POLES temperature during that period, although the air temperatures do not approach the freezing point as closely as in the other years. In 1991, the $H G$ algorithm produces a melt onset that appears too early. The al- 
gorithm indicates melt, but the other microwave parameters do not display melt characteristics until later. The POLES air temperatures show a fairly strong increase during that time period, although they are still below freezing. The discrepancies between the $H G$ algorithm and the POLES air temperatures may be in the way the air temperatures are calculated, not representing sea-ice conditions.

The $H G$ algorithm also captures melt two out of three years for the multi-year site (Figs 4-6) compared to the POLES air temperatures. In this case, an earlier melt onset is missed in 1989 by the $H G$ algorithm. The time series in 1989 shows a distinct melt event that the $H G$ temperature difference did not meet or exceed the chosen threshold while air temperatures are very close to freezing. In the other two years, the $H G$ algorithm indicates the melt onset when the air temperatures would also indicate melting in the snowpack.

To determine if these missed years could be detected better by the $H G$ algorithm, the $H G$ melt threshold was varied. If the threshold was increased (raised to 3 and then $4 \mathrm{~K}$ ) the first-year-ice locations usually showed earlier melt-onset dates to the order of several weeks to months, although melt conditions were not observed in the other microwave parameters and considered not to have taken place. The earlier melt-onset dates were indicated by the $H G$ algorithm because first-year-ice regions usually varied between 3 to $7 \mathrm{~K}$ throughout the winter. Increasing the threshold does not differentiate melt occurrences from winter conditions at the first-year-ice location. When the $H G$ threshold was increased for the multi-year-ice location, an earlier melt date was also indicated, but only in 1989 (Fig. 4). In this case, the earlier melt-onset date was probably justified. The $H G$ threshold was also decreased $(1 \mathrm{~K})$ to determine a lower sensitivity. Very little variation was observed in the melt-onset dates for the sites analyzed compared to the $2 \mathrm{~K}$ value, since the $37 \mathrm{H} \mathrm{GHz}$ TBs were observed to become larger than the $19 \mathrm{HGHz} T B$ s during melt episodes, producing a negative $H G$ value. If there was a difference in onset date, the onset date was usually delayed only a day or two. In summary, increasing the threshold mainly affected firstyear regions in a negative manner, although it might slightly benefit the multi-year location. Decreasing the threshold had little effect on onset dates for either ice-type location. Therefore, to maintain a global threshold independent of ice type, the $2 \mathrm{~K}$ threshold was retained.

Using the $2 \mathrm{~K}$ threshold, dates of initial melt onset for the entire Arctic Basin were produced from the three year dataset by the $H G$ algorithm to show the spatial distribution of melt (Fig. 7). Several generalizations can be made from this analysis. The first shows the substantial nature of the algorithm. In each year, the melt-onset dates are spatially consistent, and show the poleward progression of melt

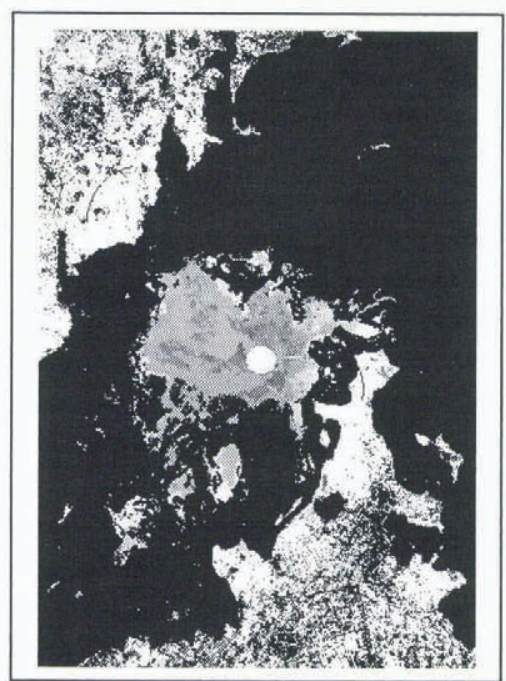

a. 1989

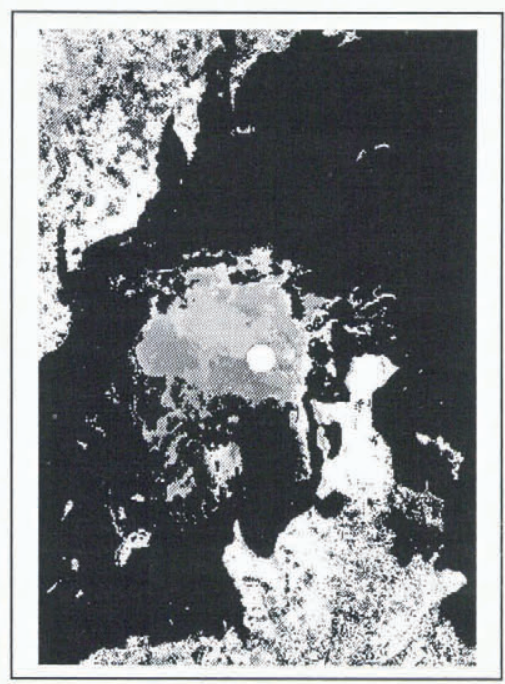

b. 1990

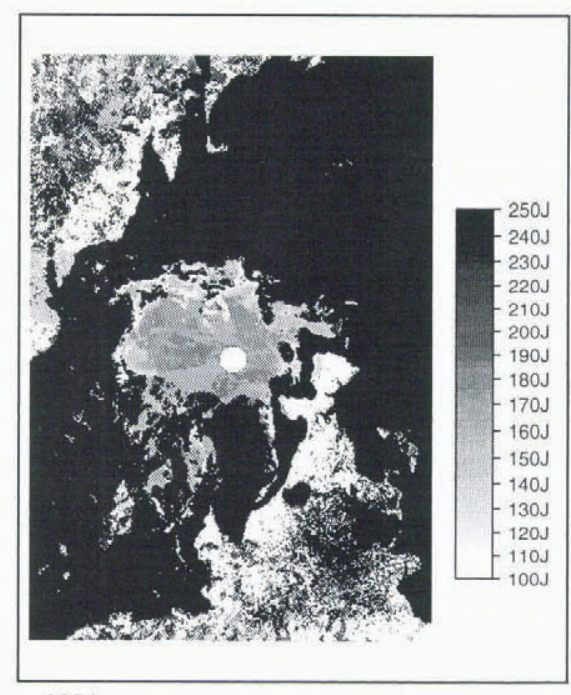

c. 1991
Fig. 7. Initial melt-onset dates as detected by the HR melt algorithm for (a) 1989, (b) 1990 and (c) 1991. 
taking place from the southern first-year-ice locations to later multi-year locations. However, linear features were observed for several locations among the years analyzed. These were further explored to determine a cause for the linear nature of the dates. For example, one of these features is located along the 135th meridian from the pole to the coast in 1991 (Fig 7c). At several locations along this linear feature, perpendicular transects were made to analyze the melt-onset dates and their TB time series.

Examining the gridcells on either side of the linear feature, it was easy to determine why the feature existed. The gridcells to the west of the feature (later onset dates) exhibited changes in the $T B$ s but these did not surpass the $H G$ threshold criteria. It was not due to missing data, but to the region not meeting the $H G$ threshold. Similar situations were found for the other years examined. The other major generalization would be that the $H G$ algorithm is consistent from year-to-year in its determination of melt-onset dates for the entire Arctic Basin. There are small variations within regions between the years analyzed, but this would be expected.

The spatial analysis also demonstrates, however, that at many locations in the ocean region that do not have an ice cover, the algorithm still analyzed a melt date. These points, usually south of $60^{\circ}$, need to be filtered and removed from the dataset. It was originally thought that these points were removed through weather filters applied to the concentration dataset before the $H G$ algorithm was applied. However, the spatial analysis gives a different picture. New filters will have to be developed and applied to ensure an accurate melt dataset in open-ocean regions.

To show that the variation in the threshold was mainly a first-year-ice problem and not a result of the initial locations investigated, spatial maps of the Arctic Basin were produced using the different threshold values for the three years studied. The first-year-ice region onset dates were generally the most affected by the variation in the threshold value. In summary, using a global threshold value will not always give the most accurate response for all locations. However, using the $2 \mathrm{~K}$ threshold appears to be the best value for the entire Arctic Basin.

\section{MELT-ONSET VARIABILITY}

To show the capabilities of the melt algorithm to produce a melt climatology, the two example sites will be further discussed, although other locations have been investigated (Table 1). Again, these sites were chosen because they represent both first-year and multi-year ice conditions. The analysis was completed for $1989-91$. The $H G$ algorithm determined that the initial melt occurred between Julian Days 123-134 for the three years (Table 1; Figs 1-3), an 11 day variation.

The time series for the multi-year-ice location, found in the central Arctic Ocean (Table 1), shows similar results (Figs 4-6). The initial melt occurrences showed a greater range than at the first-year-ice location. The $H G$ algorithm indicated that melt occurred between Julian day 138 and 174 , a 36 day variation among the three years analyzed.

It can be assumed that the actual range in dates among years for most locations is relatively small, although variations do exist. Again, this would enhance the current thinking that melt occurrence in the Arctic Basin is mainly regulated by the radiational changes that take place in the Arctic throughout the spring period. However, the variations in initial date for each location are going to be driven by local annual variations controlling the amount of solar radiation received and the atmospheric sensible heat advected into the region to initiate melt.

\section{SUMMARY}

A study was launched to develop a new melt algorithm that would detect the onset of melt for the entire Arctic sea-ice basin with no dependence on ice type. The $H G$ melt algorithm developed produces initial melt-onset dates when the sea-ice snowpack begins to show melt in the passive-microwave remotely sensed data. The melt algorithm was then applied to three years of data to show the nature of the algorithm for different ice-type locations. The results from this investigation show that the entire passive-microwave $T B$ dataset can be analyzed to produce a melt-onset date climatology. The climatology can be derived from passive microwave $T B$ s from SMMR and other SSM/I platforms. Once the climatology is produced, a more complete understanding of the relationships between atmospheric effects and ice conditions, especially considering modeled climate variations, can be investigated.

\section{ACKNOWLEDGEMENTS}

I would like to thank the two anonymous reviewers for their helpful suggestions and comments. I would also like to thank J. Maslanik for supplying the 24 hour averaged POLES temperature data. The original POLES data were obtained from the Polar Science Center, University of Washington, Seattle, WA. The SSM/I gridded-brightness temperatures obtained on CD-ROM were from the National Snow and Ice Data Center, Boulder, CO. This work was supported at the University of Nebraska by NASA grant NAGW-1266 and by NASA contract NAS-5-32392 to the University of Colorado.

\section{REFERENCES}

Abdalati, W. and K. Steffen. 1995. Passive microwave-derived snow melt regions on the Greenland ice sheet. Geophys. Res. Letl., 22 (7), 787-790.

Anderson, M. R. 1987a. The onset of spring melt in first-year ice regions of the Arctic as determined from scanning multichannel microwave radiometer data for 1979 and 1980. J. Geophys. Res., 92 (C12), 13,153-13,163.

Anderson, M. R. 1987b. Snow melt on sea ice surfaces as determined from passive microwave satellite data. International Association of Hydrological Sciences Publication, 166 (Symposium at Vancouver 1987 - Large Scale Effects of Seasonal Snow Cover), 329-342.

Anderson. M. R.. R. G. Crane and R. G. Barry. 1985. Characteristics of Arctic Ocean ice determined from SMMR data for 1979: case studies in the seasonal sea ice zone. Adv. Space Res., 5 6), 257-261.

Cavalieri, D. J., P. Gloersen and W. J. Campbell. 1984. Determination of sea ice parameters with the NIMBUS 7 SMMR. J. Geophys. Res., 89 (D4), $5355-5369$.

Mätzler, C. 1987. Applications of the interaction of microwaves with the natural snow cover. Remote Sensing Rev., 2 (2), $259-387$.

Mote, T. L. and M. R. Anderson. 1995. Variations in snowpack melt on the Greenland ice sheet based on passive-microwave measurements. F. Glaciol., $41(137), 51-60$.

Onstott, R. G., T. C. Grenfell, C. Mätzler, C. A. Luther and E. A. Svendsen. 1987. Evolution of microwave sea ice signatures during early summer and midsummer in the marginal ice zone. f. Geophys. Res., 92 (C7), 6825-6835. 